\title{
Luminal narrowing of coronary capillaries in human hypertrophic hearts: an ultrastructural morphometrical study using endomyocardial biopsy specimens
}

\author{
G Takemura, Y Takatsu, H Fujiwara
}

\begin{abstract}
Background-Abnormal microcirculation has been suggested in hearts with pathological conditions, particularly in hypertrophic hearts, even in the presence of normal epicardial coronary arteries. However, the morphology of coronary capillaries has not been well investigated in those hearts.
\end{abstract}

Methods-Ultrastructural morphometry of the capillaries in 47 endomyocardial biopsy specimens taken from 30 patients was performed.

Patients-Six patients had hypertrophic cardiomyopathy with dilated cardiomyopathy-like features (DCM-like HCM), six had HCM, six had DCM, five had postmyocarditis, and seven were normal subjects.

Results-The short axial diameters of capillaries were similar among the groups. Abnormal stenosis of more than $90 \%$ luminal narrowing was found in $31 \%$ of capillaries of the DCM-like HCM group, $16 \%$ of the HCM group, $13 \%$ of the DCM group, $11 \%$ of the postmyocarditis group, and $2 \%$ of the normal subjects. Mean (SD) stenosis of the lumen was most severe in DCM-like HCM $(78(8) \%)$, and more severe in HCM (67(9)\%), DCM (66(8)\%), and postmyocarditis $(68(4) \%)$ than normal subjects $(56(8) \%)$. The mean cross sectional areas of capillaries were similar among the groups; however, the endothelial cellular area was significantly $(\mathbf{p}<0.05)$ greater in DCM-like HCM $\left(24.2(8.2) \mu^{2}\right)$ than in normal subjects (14.7 (1.8) $\mu^{2}$ ), indicating that capillary narrowing was due to the increased volume of capillary endothelial cells. The endothelial cells of the stenosed capillaries showed severely oedematous changes of the cytoplasm wholely or partially, but the cytoplasmic organelles and nuclei appeared intact.

Conclusion-Narrowing of the coronary capillaries may be of pathophysiological significance in microcirculatory abnormality in hypertrophic hearts, particularly in patients with DCM-like HCM. (Heart 1998;79:78-85)

Keywords: capillary; hypertrophy; cardiomyopathy; ultrastructure
A reduction in coronary flow reserve has been reported in human hypertrophic hearts, especially hypertrophic cardiomyopathy (HCM), in spite of normal epicardial coronary arteries. ${ }^{12}$ A variety of mechanisms has been suggested: an augmentation of the extravascular component of coronary resistance ${ }^{2}$; an inadequate capillary density in relation to increased myocardial mass ${ }^{3}$; coronary artery $\mathrm{spasm}^{4}$; septal perforator artery compression ${ }^{5}$; abnormal arteriovenous oxygen difference ${ }^{2}$; and intramyocardial small artery disease.$^{6-14}$ Luminal narrowing of small arteries caused by intimal hyperplasia and medial hypertrophy has been reported in patients with HCM using both qualitative $^{6-13}$ and quantitative ${ }^{14}$ methods. A previous study of necropsy hearts revealed that luminal narrowing of small arteries was most severe in the ventricular septum of hearts with HCM with dilated cardiomyopathy-like features (DCM-like HCM), more severe in hearts with HCM than in normal hearts, decreased from the epicardial to the endocardial layer of the free wall, and inversely correlated with the percentage area of fibrosis. ${ }^{14}$ These observations suggest that narrowing of the small arteries is associated with an increased level of fibrosis in hearts with HCM, particularly in the ventricular septum of hearts with DCM-like HCM, and raise a possibility of a pathogenetic role of small artery disease for the progression from HCM to DCM-like HCM.

Although intramyocardial small artery disease in human hypertrophic hearts has been well investigated, only a few studies have examined morphology of the capillaries. ${ }^{15}$ In the present study, we performed a morphometrical analysis of myocardial capillaries under electron microscopy in endomyocardial biopsy specimens taken from patients with DCM-like HCM and classic HCM. Additionally, we analysed hearts with DCM, with postmyocarditis, and normal hearts, and sought roles for the capillary changes in the hypertrophic hearts.

\section{Methods}

PATIENTS

Endomyocardial biopsy specimens were taken from the right ventricle, left ventricle, or both, from 30 patients. There were 20 male and 10 female patients ranging in age from 22 to 74 years (mean (SD), 51 (13)). All patients were evaluated clinically by both non-invasive and invasive methods. The patients comprised the following five groups based on clinical, 
Table 1 Clinical data

\begin{tabular}{|c|c|c|c|c|c|c|c|c|}
\hline Group & $n$ & Age & $\begin{array}{l}\text { Sex } \\
(M / F)\end{array}$ & $C I\left(\mathrm{ml} / \mathrm{m}^{2}\right)$ & $\begin{array}{l}P C W P \\
(m m \mathrm{Hg})\end{array}$ & $\begin{array}{l}\text { LVEDVI/LVESVI } \\
\left(\mathrm{ml} / \mathrm{m}^{2}\right)\end{array}$ & $E F(\%)$ & IVST/PWT (mm) \\
\hline DCM-like HCM & 6 & $49(7)$ & $4 / 2$ & $2.5(0.7)$ & $18(10)^{\star}$ & $133(35)^{\star}+/ 104(44)^{\star} \ddagger$ & $24(17)^{\star} \neq \uparrow$ & $12(3) t / 10(1)$ \\
\hline $\mathrm{HCM}$ & 6 & 57 (18) & $5 / 1$ & $2.7(0.6)$ & $17(7)^{\star}$ & $58(12)+\$ 9 / 13(3)^{\star}+59$ & $77(8)+59$ & $25(4)^{\star}+5 \Phi / 12(3)^{\star}$ \\
\hline DCM & 6 & $55(5)$ & $5 / 1$ & $2.1(0.7)^{\star}$ & $14(8)$ & $146(57)^{\star}+/ 112(60)^{\star} \ddagger$ & $26(13)^{\star} \neq \pi$ & $10(1)+/ 10(1)$ \\
\hline Postmyocarditis & 5 & 49 (13) & $3 / 2$ & $3.0(0.7)$ & $11(3)$ & $122(65) \dagger / 69(60) \ddagger$ & $50(18)^{\star}+\ddagger \rrbracket$ & $9(2) \dagger / 9(1)$ \\
\hline Normal control & 7 & $45(15)$ & $4 / 3$ & $3.1(0.7) \mathbb{S}$ & $8(3) \dagger \ddagger$ & $69(13)+\$ / 21(9) \dagger \ddagger \emptyset$ & $69(8)+59$ & $9(1) \dagger / 9(1) \ddagger$ \\
\hline
\end{tabular}

Values are mean $(\mathrm{SD})$

Significant difference $(\mathrm{p}<0.05)$ compared with: $\left(^{\star}\right)$ control; $(\dagger)$ DCM-like HCM; $(\ddagger)$ HCM; $(\$)$ DCM; $(\mathbb{\Phi})$ postmyocarditis.

CI, cardiac index; PCWP, pulmonary capillary wedge pressure; HR, heart rate; LVEDVI and LVESVI, left ventricular end diastolic and end systolic volume index; EF, left ventricular ejection fraction; IVST and PWT, interventricular septal and left ventricular posterior wall thickness.

echocardiographic, haemodynamic, angiographic, and histological findings: six patients with DCM-like HCM, six with HCM, six with DCM, five with postmyocarditis, and seven normal control subjects without any known organic cardiac diseases (table 1). The patient selection was done in a consecutive manner in each group: the most recent consecutive patients were entered into the study who underwent endomyocardial biopsy in Hyogo Prefectural Amagasaki Hospital.

Of the six cases of DCM-like HCM, the progression from HCM to DCM-like features was demonstrated in two cases. The remaining four cases were clinically diagnosed with DCM. However, these cases showed extensive myofibre disarray mainly distributed in the biopsies taken from the right ventricle, thereby being histopathologically diagnosed with HCM. The diagnosis was also confirmed by a positive family history of HCM in all cases. All patients suffered from severe congestive heart failure, and two of the six also complained of atypical chest pain.

The diagnosis of HCM or DCM was made principally according to the definition and classification proposed by the World Health Organisation/International Society and Federation of Cardiology Task Force. ${ }^{16}$

The postmyocarditis group included patients who had clinical evidence of acute myocarditis more than one month earlier and were given the histological diagnosis of acute myocarditis at the acute stage by endomyocardial biopsy examination. The specimens of the follow up endomyocardial biopsy at the late stage, which were used in the present study, revealed persistent, healing, or healed myocarditis. The histological definition was based on the Dallas classification system. ${ }^{17}$ The postmyocarditis group was included in the present study as viruses, bacteria, and other infectious agents may cause vascular stenosis. ${ }^{18}$

The normal control group included patients who had been suspected clinically of some car- diac disease because of chest pain, minimal electrocardiographic change, or arrhythmia but for whom invasive examination of coronary angiography and biopsy findings, especially those on small arteries, were not diagnostic.

Hypertension was not evident in any patient. No case had significant extramural coronary arterial stenosis. All cases in this study were free from diseases causing narrowing of the intramyocardial small artery disease such as diabetes mellitus, polyarteritis, lupus, and amyloidosis. ${ }^{8}$

\section{ECHOCARDIOGRAPHIC, HAEMODYNAMIC, AND} ANGIOGRAPHIC EVALUATIONS

A cross sectional echocardiographic study was performed in all patients. The ventricular septal thickness and the left ventricular posterior wall thickness at diastolic phase were recorded at the mid-ventricular level.

All patients underwent both right and left heart catheterisation, biplane left ventriculography, and selective coronary angiography with standard techniques. The heart rate and pressures from the right and left heart were recorded, and the cardiac index was estimated by the thermodilution method. Left ventricular end diastolic and end systolic volume indexes and ejection fraction were calculated from the left ventricular cineangiogram.

\section{HISTOLOGICAL EVALUATION}

The biopsy procedure was performed by a Mansfield biotome (Boston Scientific Co, Cambridge, Massachusetts, USA) from the right or left ventricle, or both. There were 47 biopsy specimens used in the study (table 2).

Three to five biopsy specimens were obtained from each ventricle. The largest specimens were used for diagnostic evaluation by light microscopy. They were immediately fixed in $10 \%$ buffered formalin solution, dehydrated, embedded in paraffin wax, and cut into $4 \mu \mathrm{m}$ sections. They were stained with haematoxylin and eosin or Masson's trichrome. Histological

Table 2 Histological data

\begin{tabular}{|c|c|c|c|c|c|c|c|c|c|c|}
\hline \multirow[b]{2}{*}{ Group } & \multicolumn{2}{|l|}{$n$} & \multicolumn{2}{|c|}{ Myocyte size $(\mu m)$} & \multicolumn{2}{|c|}{ Grade of fibrosis } & \multicolumn{2}{|c|}{ Grade of disarray } & \multicolumn{2}{|c|}{ IMSA disease } \\
\hline & $\begin{array}{l}R V B \\
\end{array}$ & $L V B$ & $R V B$ & $L V B$ & $R V B$ & $L V B$ & $R V B$ & $L V B$ & $\begin{array}{l}R V B \\
\end{array}$ & $L V B$ \\
\hline DCM-like HCM & 5 & 4 & $21.7(3.9)^{\star}$ & $26.9(1.6)^{\star}$ & $2.0(0.7)^{\star}$ & $1.8(1.0)^{\star}$ & $2.2(0.4) \star 59$ & $2.3(1.0) \star \sqrt{ } \neq \uparrow$ & $1 / 5$ & $2 / 4$ \\
\hline $\mathrm{HCM}$ & 5 & 5 & $20.9(4.1)^{\star}$ & $27.5(5.0)^{\star}$ & $1.6(0.5)^{\star}$ & $1.2(0.8)^{\star}$ & $1.8(1.1)^{\star}$ & $1.2(0.4)^{\star}+5$ & $0 / 5$ & $1 / 5$ \\
\hline DCM & 5 & 5 & $19.2(3.3)^{\star}$ & $25.4(1.7)^{\star}$ & $1.8(0.8)^{\star}$ & $2.4(0.9)^{\star}$ & $0.4(0.5) \dagger \ddagger$ & $0.2(0.4) \dagger \ddagger$ & $0 / 5$ & $0 / 5$ \\
\hline Postmyocarditis & 4 & 3 & $18.3(5.8)$ & $23.6(6.1)^{\star}$ & $1.8(0.5)^{\star}$ & $2.3(0.6)^{\star}$ & $0.3(0.5) t \ddagger$ & $1.0(1.0) t$ & $0 / 4$ & $0 / 3$ \\
\hline Normal control & 6 & 5 & $12.8(2.2) \dagger \neq \S$ & $15.6(1.7)+\neq 59$ & $0.3(0.5)+\neq \$ 9$ & $0.2(0.4)+\ddagger 8$ & $0.3(0.8) \dagger \ddagger$ & $0.0(0.0) \dagger \neq$ & $0 / 6$ & $0 / 5$ \\
\hline
\end{tabular}

Values are mean (SD).

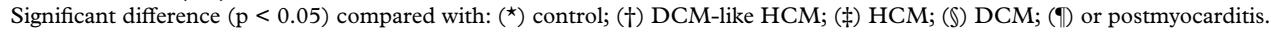

RVB and LVB, right and left ventricular biopsy; IMSA, intramyocardial small artery. 


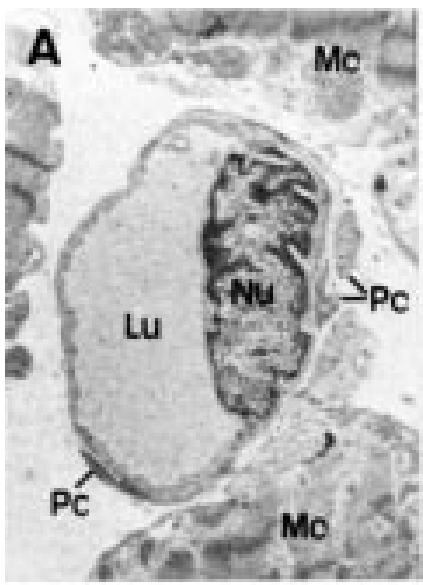

Nu, endothelial cell nucleus

Lu, capillary lumen

Pc, pericyle

Mc, myocyte

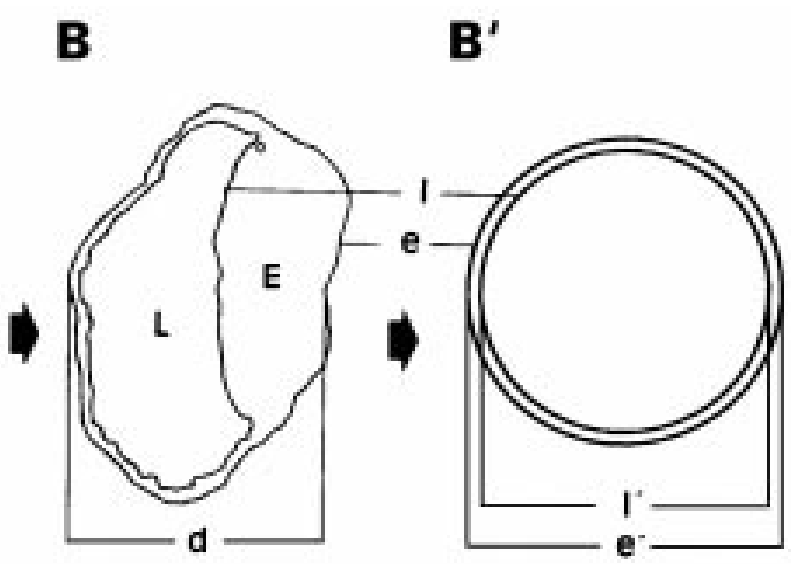

\section{d. ghort diameter}

e. endothelial cell circumference

1. luminal circumference

$\mathrm{E}$, endothelial cell area

$\mathrm{L}$, luminal area

\%Stenosis $=E N E+L) \times 100$ e., hypothetical endothelial cell diameter $\mathrm{I}$, hypothetical lumingl diameter

\section{Hypothetical \%uStenosis} $=\left\{1-\left[\text { rie }^{\prime}\right]^{2}\right\} \times 100$

Figure 1 Method for ultrastructural morphometry of coronary capillaries. On the electron micrograph of a capillary (A), the circumference of the capillary endothelial cell and of the lumen were traced as shown in panel (B). Panel (B) was then converted to panel (B'), a hypothetical state, using the measured parameters.

parameters such as myocyte size (mean diameter, 30 to 50 myocytes per specimen), degree of fibrosis (arbitrarily graded from 0 to 3 ), and degree of myofibre disarray (0 to 3 ) were evaluated. The extent of fibrosis was graded as: 0 , no fibrosis; 1 , mild, when an isolated scar or mild interstitial fibrous tissue formation, or both, was identified; 2 , moderate, intermediate between mild and severe; or 3, severe, characterised by extreme replacement scarring occupying substantial portions of the section. ${ }^{19}$ For myocardial fibre disarray, the abnormal disarray defined previously, ${ }^{20}$ was graded according to the severity and the extent in the sections as follows: 0 , no disarray; 1 , mild, only minimal and focal disarray; 2, moderate, intermediate between mild and severe; or 3, severe, disorientation of myofibres covering more than threequarters of a section. Intramyocardial small arteries were also examined.

\section{ELECTRON MICROSCOPIC PROCEDURE AND}

MORPHOMETRY

The endomyocardial biopsy specimens other than those used for light microscopy observation were immediately fixed for four hours by immersion in $2.5 \%$ glutaraldehyde dissolved in $0.1 \mathrm{M}$ phosphate buffer. They were postfixed in $1 \%$ osmium tetroxide for one hour, dehydrated in a graded series of ethanol and propylene oxide and embedded in Epon. They were thin-sectioned $(80 \mathrm{~nm})$ with an ultramicrotome, mounted on plain copper grids, stained with uranyl and lead, and examined by a Hitachi-600 electron microscope.

The thin sections were reviewed by observers who were unaware of the diagnosis. All of the capillaries in a thin section were counted. The capillaries were cut roundly in cross section (the longest and shortest diameter ratio $<2$ ) and sectioned at the level of the nuclei of capillary endothelial cells (figs 1 and 2). They were examined at $\times 2500$ to $\times 10000$ after calibration with a carbon grating replica. Negatives were processed in a standardised manner to obtain photographic prints enlarged at $\times 2.5$, so that each capillary was finally magnified at $\times 6250$ to $\times 25$ 000. Using a digitiser connected to a personal computer, the following parameters were measured in each capillary (fig 1): the short axial diameter of the capillary $(\mathrm{d}, \mu \mathrm{m})$; the external circumference of the capillary $(e, \mu \mathrm{m})$; the circumference of the lumen $(1, \mu \mathrm{m})$; the cross sectional area of the capillary endothelial cell $\left(\mathrm{E}, \mu \mathrm{m}^{2}\right)$; and the cross sectional area of the capillary lumen $\left(\mathrm{L}, \mu \mathrm{m}^{2}\right)$. From these values, the whole cross sectional area of the capillary $\left(\mathrm{A}=\mathrm{E}+\mathrm{L}, \mu \mathrm{m}^{2}\right)$ and capillary endothelial cellular area fraction (\%stenosis $=\mathrm{E} / \mathrm{A} \times 100)$ were calculated.

Stenosis of the capillary $>90 \%$ was defined as abnormal in this study. Furthermore, the diameter of the capillary lumen (in $\mu \mathrm{m}$ ) was calculated as follows: $1^{\prime}=1 / \pi$. This was a hypothetical diameter of the lumen at a hypothetical state in which the capillary lumen was stretched to make an exact circle (fig 1). In addition, a hypothetical diameter of the capillary including the endothelial cell $\mathrm{e}^{\prime}=\mathrm{e} / \pi$ was calculated (in $\mu \mathrm{m}$ ). Using these parameters, a hypothetical capillary endothelial cellular area fraction, a hypothetical percentage stenosis, was calculated as follows:

$$
\begin{gathered}
{\left[\pi\left(\mathrm{e}^{\prime} / 2\right)^{2}-\pi\left(\mathrm{l}^{\prime} / 2\right)^{2}\right] / \pi\left(\mathrm{e}^{\prime} / 2\right)^{2} \times 100=} \\
{\left[1-\left(\mathrm{l}^{\prime} / \mathrm{e}^{\prime}\right)^{2}\right] \times 100 .}
\end{gathered}
$$

Such conversion may assess the possible physiological state of the lumen, but it has the disadvantage of neglecting the area of endothelial cells.

\section{DATA ANALYSIS}

Data were expressed as mean (SD). Group comparisons were made using one-way analysis of variance followed by Newman-Keul's multiple comparisons test, or using $\chi^{2}$ analysis; $\mathrm{p}<0.05$ was considered significant. 


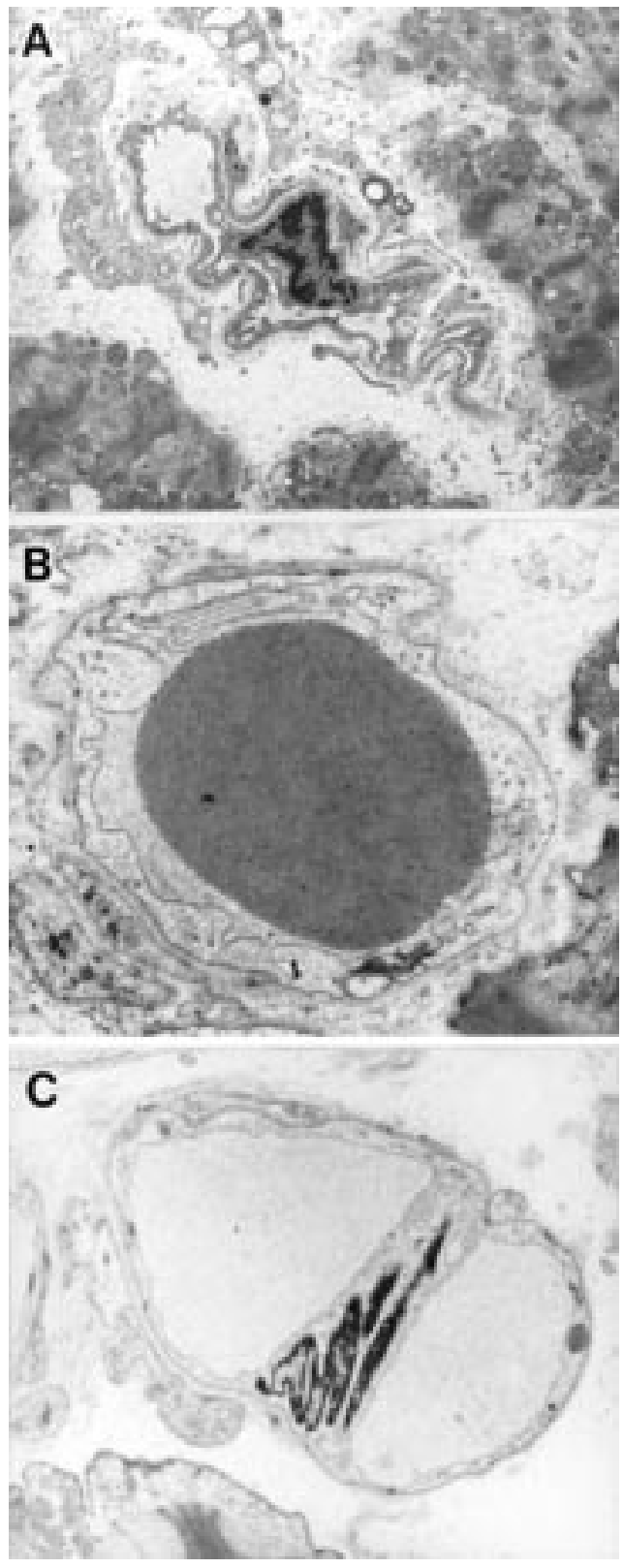

Figure 2 (A) Non-round capillaries caused by oblique transection; (B) round but not sectioned at the nucleus level of the capillary endothelial cell; $(C)$ branching capillaries. These were excluded, and only capillaries cut roundly in cross section (the longest and shortest diameter ratio $<2$ ) at the level of the nucleus were examined. (Original magnifications, $(A) \times 1700$; $(B) \times 5000$; (C) $\times 2500$.)

\section{Results}

HAEMODYNAMIC AND HISTOLOGICAL DATA

Table 1 shows clinical data including haemodynamics of each group. There was no significant difference in age or sex among the groups. The left ventricle was more severely dilated in the DCM-like HCM, DCM, and postmyocarditis groups than the HCM and normal subjects as indicated by the left ventricular end diastolic and end systolic volume indexes. Cardiac contractility (ejection fraction) was most severely impaired in the DCM-like HCM and DCM groups, and more severely in the postmyocarditis group compared with the HCM or normal groups. The ventricular septal wall thickness was profoundly thick in the HCM group, but was similar among the other four groups.

Table 2 shows histological parameters of each group. Myocyte size was significantly greater and fibrosis was more severe in the groups with diseased hearts compared with normal subjects. Myofibre disarray was more severe in the DCM-like HCM and HCM groups than in the DCM, postmyocarditis, or control group. Narrowings of intramyocardial small arteries were found in two of six patients with DCM-like HCM and one of six patients with HCM, but in none of the patients with DCM or postmyocarditis, and in none of the normal subjects.

CAPILLARY MORPHOMETRY

A total of 603 capillaries were measured: 97 in DCM-like HCM, 139 in HCM, 134 in DCM, 94 in postmyocarditis, and 139 in the normal subjects. Table 3 summarises the capillary morphometrical data.

The external diameter of the capillaries ranged from $1.7-17.2 \mu \mathrm{m}$, and the mean value was similar among the groups. Luminal circumference (1) and external circumference (e) of the capillaries were similar among the groups. However, the circumference ratio (1:e) was significantly smaller in the DCM-like HCM than in the control group. The cross sectional area of the capillary $(\mathrm{A}=\mathrm{E}+\mathrm{L})$ was not significantly different among the groups. The luminal area (L) was significantly smaller in the DCM-like HCM than the normals. The cross sectional area of the capillary endothelial cell (E) was significantly increased in the DCM-like HCM compared with controls. It was also increased in other hypertrophic groups, but not significantly.

The capillaries with abnormal stenosis as defined in this study $(>90 \%)$ were most frequently found in the group with DCM-like HCM in which more than $30 \%(31(18) \%)$ of the capillaries showed abnormal luminal narrowings among all the capillaries counted. This incidence was significantly higher than that of the controls $(2(4) \%, p<0.01)$. Such capillaries were found in $16(12) \%, 13(12) \%$, and $11(11) \%$ of the groups with HCM, DCM and postmyo-

Table 3 Capillary parameters

\begin{tabular}{|c|c|c|c|c|c|c|c|c|c|}
\hline Group & $\begin{array}{l}\text { Patients } \\
\text { (n) }\end{array}$ & $\begin{array}{l}\text { Capillaries } \\
\text { examined (n) }\end{array}$ & $\begin{array}{l}\text { Mean (SD) } \\
\text { capillaries } \\
\text { examined/ } \\
\text { patient }\end{array}$ & $\begin{array}{l}\text { External } \\
\text { diameter } \\
(\mu m)\end{array}$ & $\begin{array}{l}\text { Capillary } \\
\text { luminal area } \\
\left(\mu m^{2}\right)\end{array}$ & $\begin{array}{l}\text { Capillary } \\
\text { endothelial cell } \\
\text { area }\left(\mu m^{2}\right)\end{array}$ & $\begin{array}{l}\text { Whole capillary } \\
\text { area }\left(\mu m^{2}\right)\end{array}$ & Stenosis (\%) & $\begin{array}{l}\text { Hypothetical } \\
\text { stenosis (\%) }\end{array}$ \\
\hline DCM-like HCM & 6 & 97 & $16(3)$ & $5.0(0.5)$ & $6.7(1.9)^{\star}$ & $24.2(8.2)^{\star}$ & $30.8(7.2)$ & $78(8)^{\star} \ddagger 59$ & $35(4) \star \sqrt{5}$ \\
\hline $\mathrm{HCM}$ & 6 & 139 & $23(11)$ & $4.9(1.2)$ & $14.6(12.6)$ & $20.6(8.9)$ & $35.2(21.2)$ & $67(9)^{\star}+$ & $30(7)$ \\
\hline DCM & 6 & 134 & $22(9)$ & $5.1(2.2)$ & $14.8(14.7)$ & $20.0(7.6)$ & $34.9(22.0)$ & $66(8)^{\star} \dagger$ & $27(3)$ \\
\hline Postmyocarditis & 5 & 94 & $19(12)$ & $4.5(0.9)$ & $10.4(6.4)$ & $17.7(8.7)$ & $28.1(14.9)$ & $68(4)^{\star} \dagger$ & $30(6)$ \\
\hline Normal control & 7 & 139 & $20(10)$ & $4.9(0.4)$ & $13.0(3.6) \dagger$ & $14.7(1.8) \dagger$ & $27.9(4.2)$ & $56(8) \dagger \neq 5$ & $24(6) \dagger$ \\
\hline
\end{tabular}

Significant difference $(\mathrm{p}<0.05)$ compared with: $\left(^{\star}\right)$ control; $(\dagger)$ DCM-like HCM; ( ) HCM; (\$) DCM; ( $)$ postmyocarditis. 

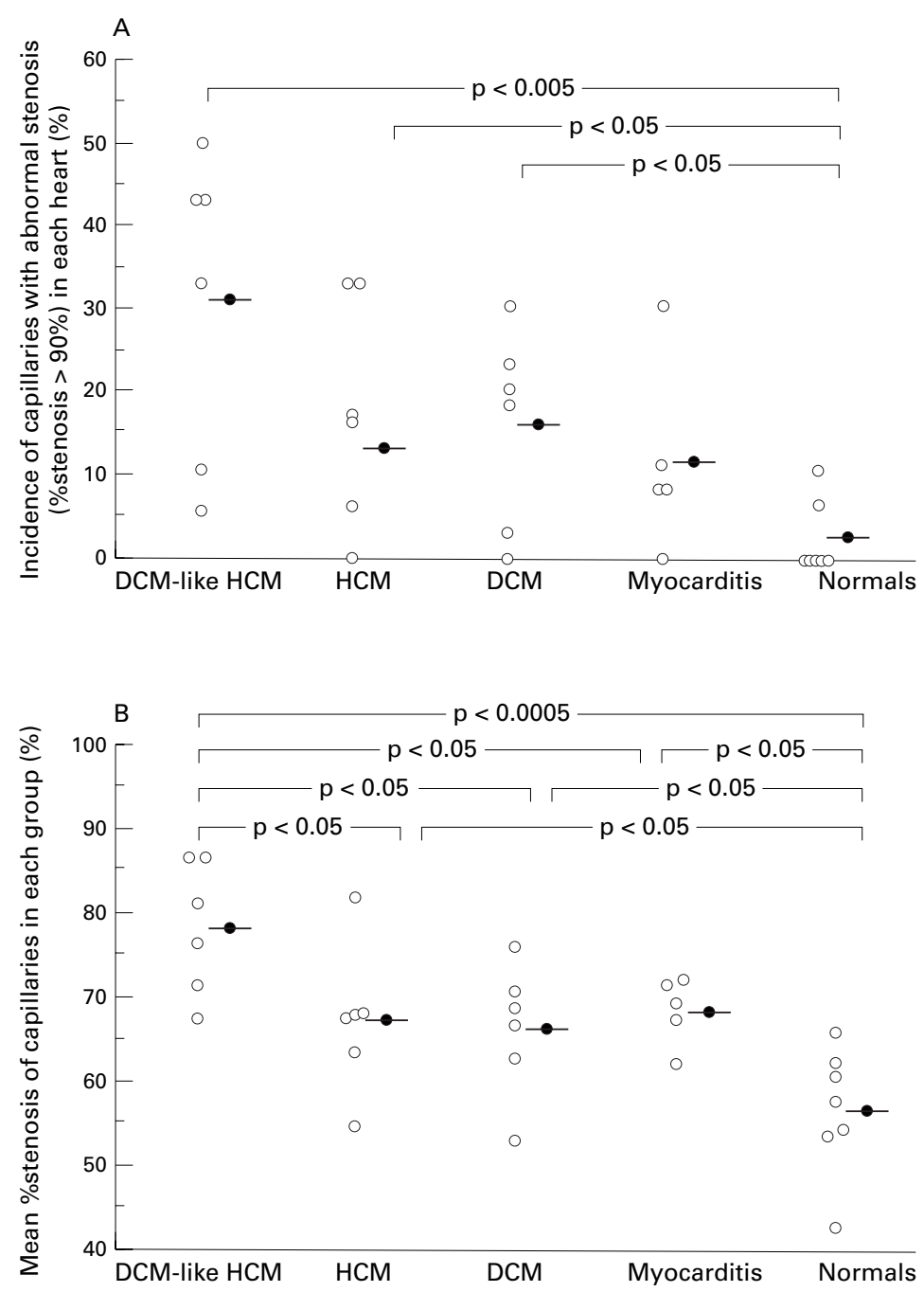

Figure 3 (A) Number of the capillaries with abnormal stenosis (>90\%) in each group. (B) Mean percentage stenosis of the capillaries in each group.

carditis, respectively (fig 3A). Mean percentage stenosis was most severe in the DCM-like HCM group, and more severe in the HCM, DCM, and postmyocarditis groups compared with the control group (table 3 and fig 3B).

Neither the luminal nor capillary diameter at a hypothetical state was significantly different among the groups. Mean hypothetical percentage stenosis was significantly greater in the DCM-like HCM group than in the control group. It showed no difference among the HCM, DCM, postmyocarditis, and control groups (table 3 ).

RELATIONS OF CAPILLARY NARROWING TO OTHER HAEMODYNAMIC AND HISTOLOGICAL VARIABLES There was no correlation between the percentage stenosis of capillaries and any haemodynamic variables (data not shown). However, there was a weak but significant positive correlation between the percentage stenosis of capillaries and size of myocytes $(r=0.396$, $\mathrm{p}<0.01)$. Severity of both myocardial fibrosis and myofibre disarray also positively correlated with that of capillary stenosis $(r=0.413$, $\mathrm{p}<0.01$ and $r=0.546, \mathrm{p}<0.001$, respectively).
CAPILLARY ULTRASTRUCTURE

In capillaries with severe stenosis, the capillary endothelial cells protruded so much into the capillary lumens that the lumens were very small and often slit-like (fig 4). The contour on the luminal side of some of those endothelial cells showed marked protrusion and invagination. Such endothelial cells had increased cytoplasm, homogeneously or heterogeneously (fig 4). However, there were no significant changes in cytoplasmic organelles including the number of pinocytotic vesicles. Their nuclei appeared normal without degenerative changes as seen following ischaemic insult.

\section{Discussion}

Although there are numerous ultrastructural descriptions of cardiac myocytes in human hypertrophic hearts, ${ }^{21-23}$ studies of their myocardial capillaries are surprisingly rare.$^{15}$ In the present study, we demonstrated a significant stenosis of the coronary capillary lumens in hypertrophic hearts compared with normal hearts. This stenosis was noted in the hypertrophic hearts regardless of the aetiology of hypertrophy: unknown, genetic, or inflammatory. It was also shown that narrowings of the capillary lumens were most conspicuous in hearts with DCM-like HCM among the examined groups with hypertrophic hearts. Furthermore, it was revealed that the capillary luminal stenosis was associated with increased volume of capillary endothelial cells in the diseased hearts with hypertrophy while the capillary area, including the endothelial cell and the lumen, was similar among the groups. These endothelial cells had increased cytoplasm, but contained cytoplasmic organelles including many pinocytotic vesicles with normal appearance. Their nuclei also appeared normal without clearing the centre of the nucleus or abnormal margination of condensed chromatin. Such ultrastructural features of the capillary endothelial cells were apparently different from those seen in ischaemic damage. ${ }^{24}$ Thus, a certain unknown but definite change might have occurred in the capillary endothelial cells, which caused the capillary lumen stenosis in the hypertrophic hearts. However, more details on such changes should be elucidated in further studies.

Narrowing of intramyocardial small arteries, on the other hand, is suggested to be one of the possible mechanisms of the reduction in coronary flow reserve and fibrosis formation in hypertrophic hearts. ${ }^{114}$ The narrowings are due to the intimal and/or medial hypertrophy of the small artery walls. Hearts with DCMlike HCM have massive fibrosis, particularly in the ventricular septum. ${ }^{12-14}{ }^{25} \mathrm{~A}$ previous study reported that degree of stenosis of intramyocardial small arteries was more severe in DCMlike HCM than in typical HCM. ${ }^{14}$ Thus, narrowings of intramyocardial small arteries may be important to the pathogenesis of massive fibrosis, which causes reduced contractility of the left ventricle in DCM-like HCM. In the present study, we found luminal stenosis also at the capillary level in the hypertrophic hearts, especially in the hearts with DCM-like HCM. 
The lumens of the severely stenosed capillaries looked too small (slit-like) for blood cells to pass through. The passage may be possible considering the deforming ability of blood cells but, at least, blood flow would be decelerated. Our data are based on observations from
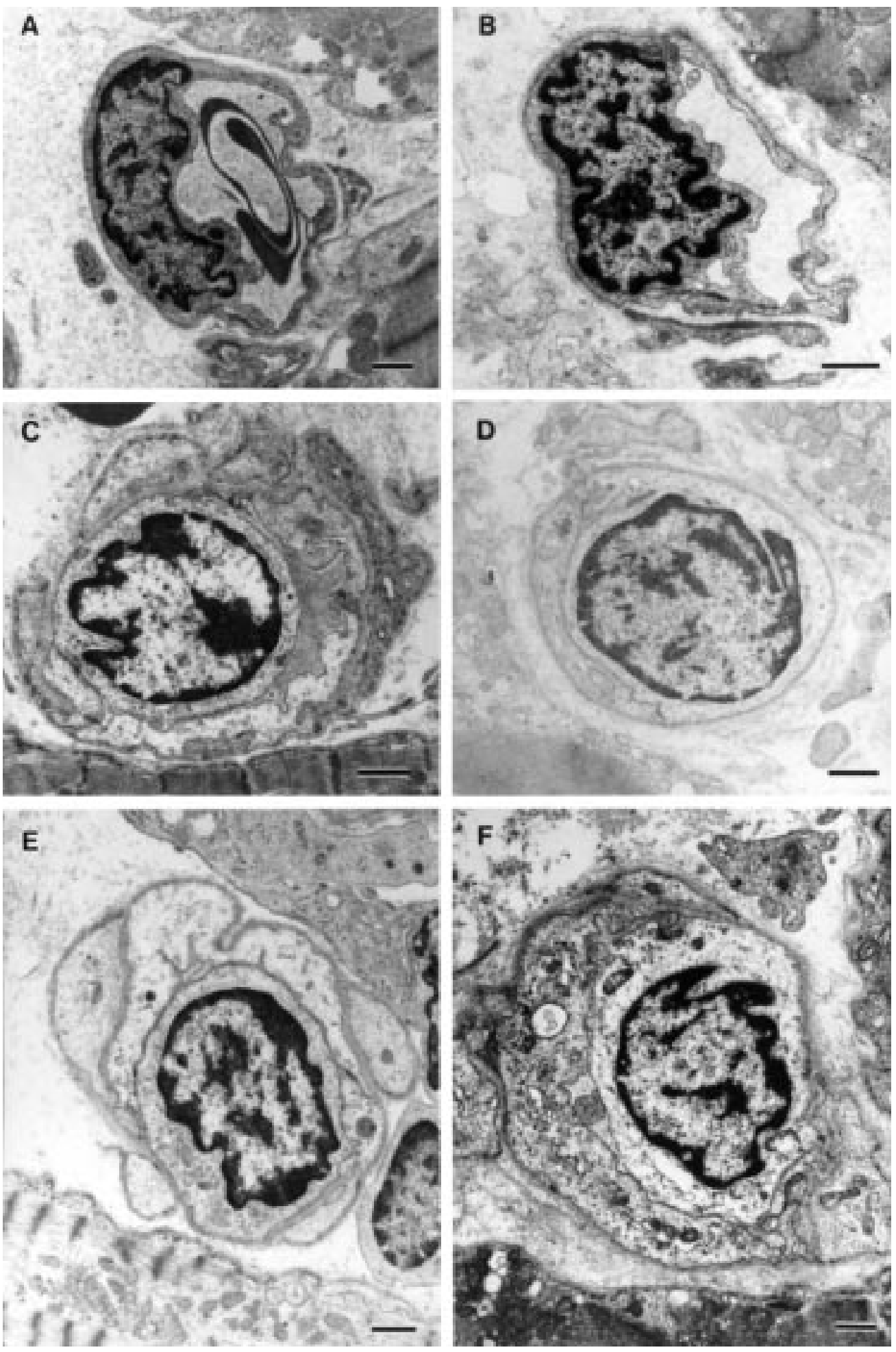

Figure 4 Electronmicrographs of the coronary capillaries with various degrees of stenosis. (A) Capillary from a control subject with stenosis of $60 \%$. A profoundly deformed red blood cell is observed in the lumen (original magnification, $\times 3900)$. (B) A capillary from a patient with HCM with stenosis of $71 \%(\times 5800)$. (C-F) Severely stenosed capillaries from patients with DCM-like HCM. Stenoses of the capillary lumens are (C) $87 \%$, (D) $98 \%,(E)$ ) $99 \%$, (F) $97 \%$. In $(C)$ and $(E)$, the capillary endothelial cells are unevenly thickened, and almost diffusely in $(F)$. There is no conspicuous thickening of the endothelial cells in (D), but the lumen is slit-like. (Original magnifications: $(C$ and D) $\times 5000$; (E) $\times 4300$; (F) $\times 4000$; bar $=1 \mu \mathrm{m}$.) 
narrowing in the capillary can reduce flow distal to it. This makes the demonstration of many narrowed capillaries in a small ultrathin section of hypertrophic hearts more significant with respect to the reduction in coronary reserve.

We also found a positive correlation between percentage stenosis of the capillaries and grade of myocardial fibrosis. Therefore, as with stenosis of intramyocardial small arteries in hypertrophic hearts, especially in DCM-like HCM, stenosis of capillaries might be another possible mechanism of the reduction in coronary flow reserve (ischaemia) and thus of fibrosis formation in hypertrophic hearts. However, the percentage stenosis was also positively correlated with myofibre disarray; therefore, the possibility of an inverse cause and effect relation should also be considered in that these narrowings might be secondary changes resulting from alterations of myocardial tissue properties.

Mosseri et $a l^{15}$ reported enlarged capillaries in biopsy specimens from hearts with DCM in their ultrastructural morphometry. They showed that the capillaries of DCM had greater cross sectional area (lumen plus wall, $\left.45.3(15.1) \mu \mathrm{m}^{2}\right)$ and lumen area $\left(17.6(6.9) \mu^{2}\right)$ than those of controls (22.7 (8.3) $\mu \mathrm{m}^{2}$ and $11.6(6.2) \mu \mathrm{m}^{2}$, respectively). The stenosis of the capillaries calculated by these values was approximately $61 \%$ in DCM and $50 \%$ in controls. Those results are similar to the data on the capillaries of DCM in the present study (table 3). However, we used more strict criteria for the selection of the capillaries to minimise the morphometrical bias due to the measured portion; only capillaries sectioned with the longest and shortest diameter ratio $<2$ and cut at the level of the nucleus of the endothelial cell were used. In addition, for morphometry, the capillary pericytes and basement membranes were excluded because distribution of pericytes are considerably variable according to the sectioned portions, and the borders of basement membranes are sometimes fuzzy and difficult to identify clearly.

As endomyocardial biopsy can examine only the subendocardium of the right ventricular septum and left ventricular free wall, the present results may not fully reflect the whole myocardium. On the other hand, unlike a necropsy study, a biopsy study has merit in analyses of relations between structure and function, and autolysis is absent. However, it is well known that endomyocardial biopsies cause artefactual changes such as mechanical trauma as a consequence of the biting and pulling by the catheter biotome and the excessive shrinkage of the tissue by the fixatives. ${ }^{26}{ }^{27} \mathrm{~A}$ biopsy specimen always suffers from this serious problem, and awareness of its occurrence is essential. As we carefully selected the capillaries using the aforementioned criteria, we believe we could have excluded the capillaries with apparent artefactual changes of compression and excessive distortion from the present analysis. Furthermore, we calculated the hypothetical morphometrical values. The capillary luminal narrowings were demonstrated in hypertrophic hearts also at the hypothetical state. However, it is not know whether this hypothetical state is ideal because this method apparently neglects the areas of the capillary endothelial cells. Thus, we have regarded the hypothetical data as supplementary.

In summary, we found many stenosed capillaries due to increased volume of endothelial cells in hypertrophic hearts, particularly DCMlike HCM, which correlated with myocardial tissue alterations. Such narrowings may be of pathophysiological significance in human hypertrophic hearts.

We thank $\mathrm{Mr}$ Naoshi Kohrogi for technical assistance in electron microscopy. We also thank Drs Koh Ono, Mayumi Ono, Toshiaki Izumi, Kazuaki Kataoka, Yuzo Takeuchi, Haruyasu Itoh, and Hidemitsu Tankawa for helpful discussion.

1 Weiss MD, Ellis K, Sclacca RR, et al. Myocardial blood flow in congestive and hypertrophic cardiomyopathy. Circulation 1976;54:484-94.

2 Cannon RO III, Rosing DR, Maron BJ, et al. Myocardial ischemia in patients with hypertrophic cardiomyopathy: contribution of inadequate vasodilator reserve and elevated left ventricular filling pressure. Circulation 1985; 71:232-43.

3 Rakusan K. Quantitative morphology of capillaries of the heart: number of capillaries in animal and human hearts under normal and pathologic conditions. Methods and Achievements in Experimental Pathology 1971;5:272-86.

4 Nishimura K, Nosaka H, Saito T, et al. Another possible mechanism of angina in hypertrophic cardiomyopathy [abstract]. Circulation 1983;68(suppl III):III-162.

5 Pichard AD, Meller J, Teichholz LE, et al. Septal perforator compression (narrowing) in idiopathic hypertrophic subaortic stenosis. Am f Cardiol 1977;40:310-14.

6 Maron BJ, Epstein SE, Roberts WC. Hypertrophic cardiomyopathy and transmural myocardial infarction without significant atherosclerosis of the extramural without significant atherosclerosis of the extram
coronary arteries. Am $\mathcal{F}$ Cardiol $1979 ; 43: 1086-102$.

7 Warnes CA, Maron BJ, Roberts WC. Massive cardiac Warnes CA, Maron BJ, Roberts WC. Massive cardiac
ventricular scarring in first degree relatives with hyper-

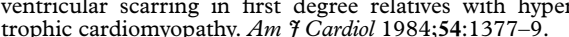

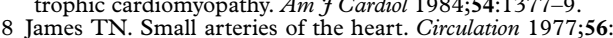
James 14.

9 James TN, Marshall TK. De subitaneis morbitus. XII. Asymmetrical hypertrophy of the heart. Circulation 1975; 51:1149-66.

10 McReynolds RA, Roberts WC. The intramural coronary arteries in hypertrophic cardiomyopathy [abstract]. $A m \mathcal{F}$ Cardiol 1975;35:154.

11 Maron BJ, Wolfson JK, Epstein SE, et al. Intramural ("small vessel") coronary artery disease in hypertrophic cardiomyopathy. F Am Coll Cardiol 1986;8:545-57.

12 Fujiwara $\mathrm{H}$, Onodera $\mathrm{T}$, Tanaka $\mathrm{M}$, et al. Progression from hypertrophic obstructive cardiomyopathy to typical dilated cardiomyopathy-like features in the end stage. fpn Circ $\mathcal{F}$ cardiomyopathy-like

13 Onodera T, Fujiwara H, Tanaka $\mathrm{M}$, et al. Familial hypertrophic cardiomyopathy mimicking typical dilated hypertrophic cardiomyopathy mimicking typic
cardiomyopathy. fpn Circ $\mathcal{F} 1986 ; 50: 614-19$.

14 Tanaka M, Fujiwara H, Onodera T, et al. Quantitative analysis of narrowing of intramyocardial small arteries in normal hearts, hypertensive hearts, and hearts with hypertrophic cardiomyopathy. Circulation 1987;75: 1130-9.

15 Mosseri M, Schaper J, Admon D, et al. Coronary capillaries in patients with congestive cardiomyopathy or angina pectoris with patent main coronary arteries. Ultrastructural morphometry of endomyocardial biopsy samples. Circulation 1991;84:203-10.

16 Report of the WHO/ISFC task force on the definition and classification of cardiomyopathies. Circulation 1996;93: 841-2.

17 Aretz HT, Billingham ME, Edwards WD, et al. Myocarditis: a histopathologic definition and classification. $A m \dot{f}$ Cardiovasc Pathol 1986;1:3-14.

18 Manion W. Inflammations of the arterial wall and vasa vasorum and their role in the pathogenesis of atherosclerosis and arterial occlusion. In: James TN, Keyes JW, eds. The etiology of myocardial infarction. Boston: Little Brown \& Co, 1963:255-62.

9 Edwards WD. Myocarditis and endomyocardial biopsy. Cardiol Clin 1984;2:647-56.

20 Fujiwara H, Kawai C, Hamashima Y. Myocardial fascicle and fiber disarray in $25 \mu$-thick sections. Circulation 1979;59:1293-8.

21 Kawamura K, James TN. Comparative ultrastructure of cellular junctions in working myocardium and the conducting
system under normal and pathologic conditions. $\mathcal{F} \mathrm{Mol} \mathrm{Cell}$ Cardiol 1971;3:31-60.

22 Marron BJ, Ferrans VJ, Roberts WC. Ultrastructural features of degenerated cardiac muscle cells in patient with cardiac hypertrophy. Am f Pathol 1975;79:387-434. 
23 Baandrup U, Florio RA, Roters F, et al. Electron microscopic investigation of endomyocardial biopsy samples in hypertrophy and cardiomyopathy. Circulation 1981

24 Kloner RA, Rude RE, Carlson N, et al. Ultrastructural evidence of microvascular damage and myocardial cell injury after coronary artery occlusion: which comes first? Circulation 1980;62:945-52.

25 Yutani C, Imakita $\mathrm{M}$, Ishibashi-Ueda $\mathrm{H}$, et al. Three autopsy cases of progression to left ventricular dilatation in patients with hypertrophic cardiomyopathy. Am Heart $\mathcal{f}$ 1985,109:545-53.

26 Sonnenblick EH. Correlation of myocardial ultrastructure and function. Circulation 1968;38:29-44

27 Olmesdahl PJ, Gregory MA, Cameron EWJ. Ultrastructural artefacts in biopsied normal myocardium and their relevance to myocardial biopsy in man. Thorax 1979;34: 82-90.

\section{IMAGES IN CARDIOLOGY}

\section{Left atrial ball thrombus}
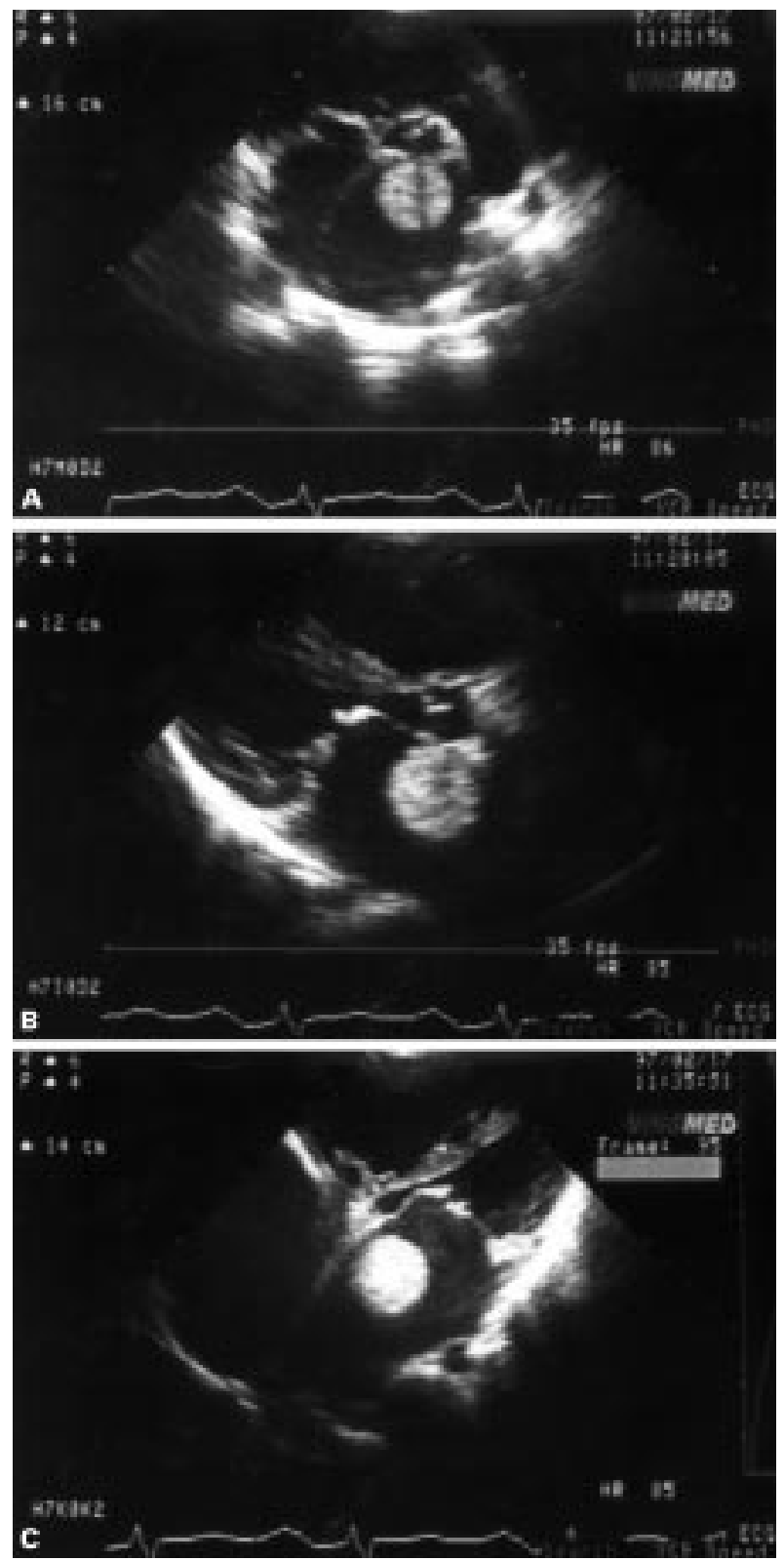

A 13 year old girl with rheumatic mitral valve disease was referred for surgical repair. She became symptomatic eight months before admission with dyspnoea and several episodes of pulmonary oedema. On arrival at our centre she was in sinus rhythm and was New York Heart Association (NYHA) grade III-IV despite maximal treatment.

Transthoracic echocardiography revealed a severe mitral stenosis. The left atrium was severely enlarged at $4.5 \mathrm{~cm}$ with a large ball thrombus $2.6 \mathrm{~cm}$ in diameter. Short axis (A), long axis (B), and modified four chamber (C) views showed the ball thrombus located above the anterior mitral leaflet, posterior to the aorta, which seemed attached to the anterior left atrial wall. Note the thickened mitral valve leaflets.

The patient was started on warfarin. After 48 hours she presented with left hemiparesis. Echocardiography showed that the thrombus had disappeared. Right carotid ultrasound revealed the presence of a thromboembolus at the bifurcation of the internal and external carotid bifurcation. The thrombus was surgically removed.

Four weeks later she underwent mitral and tricuspid valve repair. No residual thrombus was seen in the left atrium. Postoperative course was favourable with the patient in NYHA grade I and a complete recovery from the hemiparesis eight weeks after surgery.

Left atrial ball thrombi are well described in adults with longstanding mitral stenosis and atrial fibrillation. Reports in paediatric patients are uncommon especially in the absence of atrial fibrillation. Despite reports of successful resolution with warfarin treatment, it may be preferable to submit these patients to urgent surgery for thrombus removal and mitral valve repair, because of the risk of systemic emboli. 